\title{
Design and In vitro Evaluation of a Novel Sustained Release Double Layered Tablets of Lornoxicam by using semi synthetic polymers
}

\author{
Shivanand Kalyanappa*, Muppa Rama Krishna and Divakar Goli \\ Department of Pharmaceutics, Acharya \& B. M Reddy College of Pharmacy, Bangalore - 560090, INDIA.
}

\begin{abstract}
The objective of the present study was to develop double layered tablets of lornoxicam, a highly potent nonsteroidal anti-inflammatory drug. Double layered tablets compris of fast release layer and a sustained release layer, anticipating the rapid drug release that starts in the stomach rapidly alleviate the symptoms and continuous in the intestine to maintain the prolonged analgesic effect. Double layered tablets are characterized by initial drug release in the stomach and comply the requirements of sustained release portion of the dosage form. An inclusion complex of lornoxicam with $\beta$-cyclodextrin at 1:2 (drug: $\beta-C D$ ) molar ratio, was incorporated in the fast release layer to increase the release rate of lornoxicam in the stomach to produce rapid analgesic effect. Hydroxy propyl methyl cellulose (HPMC), a hydrophilic matrix forming agent, was integrated in the sustained release layer to provide the sustainment of drug release, F2 was selected as the best formulation as it fulfilled all the criteria. The drug release of F2 extended up to $12 \mathrm{~h}$ period. Based on the statistical analysis the drug release follows Anomalous diffusion mechanism. Two months of short term stability study were carried out at $30 \pm 2{ }^{\circ} \mathrm{C} / 65 \pm$ $5 \% \mathrm{RH}$ and $40 \pm 2{ }^{\circ} \mathrm{C} / 75 \pm 5 \% \mathrm{RH}$ for the best selected formulation. The results showed that there were no significant changes in all the parameters evaluated for the best formulation.
\end{abstract}

Key words: $\beta$-cyclodextrin, Double layered tablets, Lornoxicam, NSAID's, Sustained release.

\section{INTRODUCTION}

Lornoxicam is also known as chlortenoxicam, and belongs to oxicam group of non-steroidal anti-inflammatory drugs (NSAIDs). ${ }^{1}$ Lornoxicam is highly potent anti-inflammatory and analgesic properties. It is widely used for the inflammation in patients with rheumatoid arthritis, osteoarthritis and symptomatic treatment of pain. ${ }^{2}$ Moreover, lornoxicam shows efficacy in clinical management of preoperative and postoperative pain associated with gynecological, dental and orthopedic surgeries. ${ }^{3}$ However its usage is limited mainly because of its shorter half-life $(4 \mathrm{~h})$. Lornoxicam exhibits $\mathrm{pH}$ dependent solubility, it shows very poor solubility in acidic conditions (in stomach) and gets in contact with the stomach mucosa for a longer period of time and causes irritation and leads to ulceration. So to reduce the contact with stomach mucosa lornoxicam was complexed with cyclodextrin and also it increases the solubility of lornoxicam. ${ }^{4}$

The layered tablet concept has been utilized to develop controlled-release formulations. ${ }^{5}$ Such a tablet is considered as a biphasic delivery system that is designed to release the drug at two different rates and is usually composed of a fast-release layer combined with single or double sustained-release layers. ${ }^{6}$ Generally, conventional controlledrelease dosage forms delay the release of drugs and do not provide a rapid onset of action after oral administration. Hence, the layered tablets offer a pharmacokinetic advantage over conventional controlledrelease dosage forms as the drug is quickly released from the fast-release layer leading to rapid rise of drug plasma concentration followed by continuation of drug release
Submission Date : 15-03-2013 Revision Date : :22-09-2014 Accepted Date : :02-04-2015

DOI: $10.5530 /$ ijper.49.4.5 Correspondence Address Mr. Shivanand Kalyanappa Department of Pharmaceutics, Acharya \& B. M Reddy College of Pharmacy, Bangalore-560090, India Email:shivanand@acharya ac.in

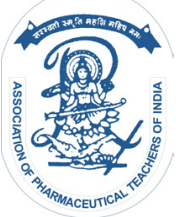

www.ijper.org 


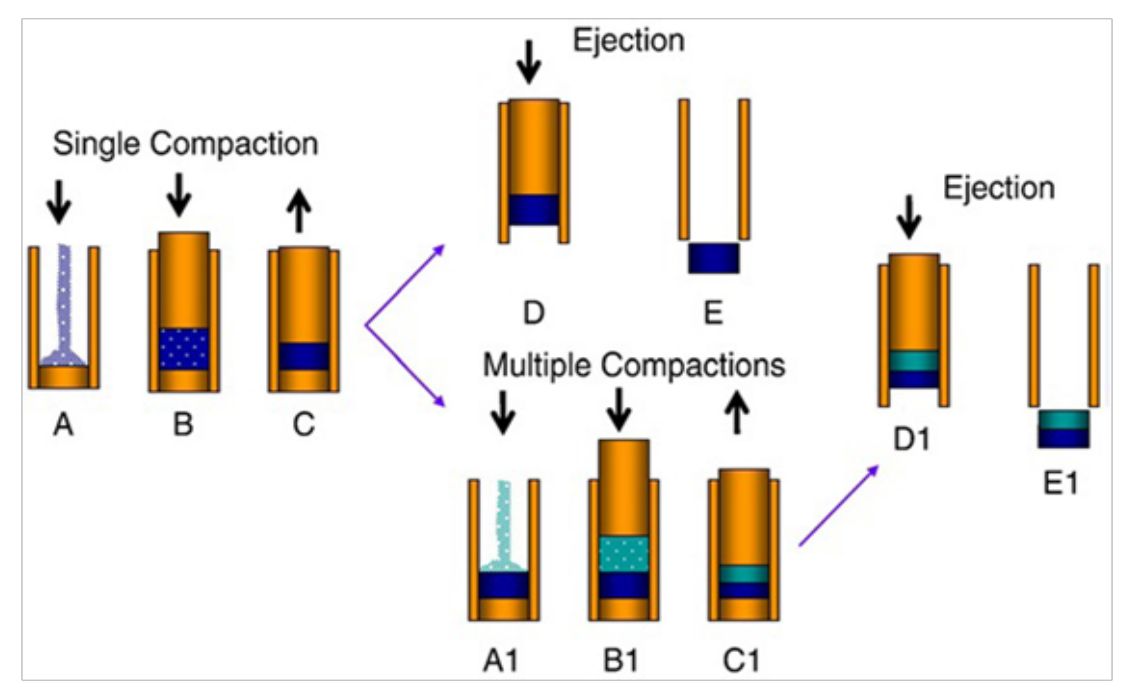

Double layered tablets compris of fast release layer and a sustained release layer, anticipating the rapid drug release that starts in the stomach rapidly alleviate the symptoms and continuous in the intestine to maintain the prolonged analgesic effect.

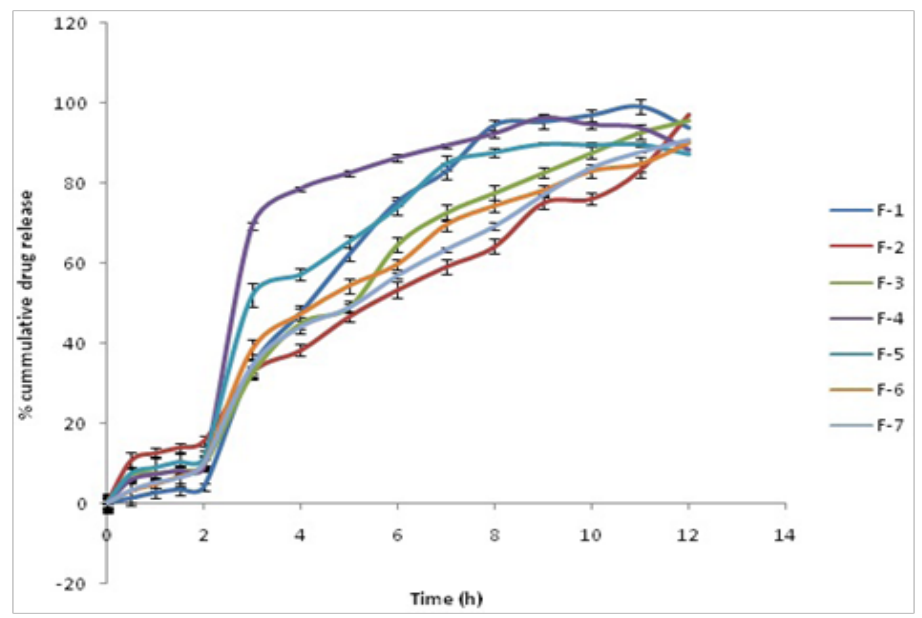

The drug release of F2 extended up to $12 \mathrm{~h}$ period. Based on the statistical analysis the drug release follows Anomalous diffusion mechanism.

\section{Graphical Abstract}

from the sustained release layer. This release pattern is required for successful treatment in many therapies, primarily when maximum relief needs to be achieved as soon as possible, and is followed by a sustainedrelease phase to avoid repeated drug administration. It is reported that the NSAIDs are suitable candidate drugs for this type ofadministration.

Accordingly, the current study was undertaken to modify the release pattern of lornoxicam through its incorporation in an oral dosage form that is able to promptly release lornoxicam in a soluble form in the stomach with the aim to reaching high serum concentration in a short period of time, ensuring rapid palliative effect for the symptoms. This action is then followed by an extended release of lornoxicam for more than $12 \mathrm{~h}$ to avoid its repetitive administration.
Cyclodextrins (CDs) are a group of cyclic oligosaccharides, which have been investigated to improve the solubility and dissolution rate of various poorly soluble drugs. Moreover, CDs have been successfully employed to modify the release pattern of drugs in several modified release formulations. In addition, it has been reported that the local gastric irritation/ulceration associated with the oral use of NSAIDs is extensively reduced by averting their direct contact with the stomach wall through their entrapment and inclusion in the hydrophobic cavity of CDs. ${ }^{8}$ According to the aforementioned reasons, natural parent $\beta$-cyclodextrin $(\beta-C D)$, were investigated for their suitability to be included in the fast-release layer of the DLTs. Hydroxy Propyl Methyl Cellulose (HPMC) was chosen as the candidate matrix-forming material to obtain suitable slow release of thedrug from the sustained-release layer present in the prepared DLTs 


\begin{tabular}{|c|c|}
\hline $\begin{array}{c}\text { Table 1: Formulation of the immediate release } \\
\text { layer }\end{array}$ \\
\hline $\begin{array}{c}\text { INGREDIENTS } \\
\begin{array}{c}\text { QUANTITY TAKEN } \\
\text { PER TABLET } \\
\text { complex }\end{array}\end{array}$ & $\begin{array}{c}13.33 \mathrm{mg} \approx 4 \mathrm{mg} \text { of } \\
\text { lornoxicam }\end{array}$ \\
\hline Croscarmellose sodium & $5 \mathrm{mg}$ \\
\hline $\begin{array}{c}\text { Sodium carboxy methyl } \\
\text { cellose }\end{array}$ & $5 \mathrm{mg}$ \\
\hline Magnesium stearate & $2 \mathrm{mg}$ \\
\hline Lactose & qs to $100 \mathrm{mg}$ \\
\hline
\end{tabular}

due to its biocompatibility, inertness, ${ }^{9}$ as well as its wide application as a sustained-release excipient. ${ }^{10}$

In order to reach the goal of this study, solid systems of lornoxicam with $\beta$-CD were prepared using different techniques, aiming to improve lornoxicam dissolution properties in acidic medium, as a primary step in development of DLTs. ${ }^{11}$ The interaction between lornoxicam and the $\mathrm{CD}$ was investigated in solution state usingphase solubility and in solid state using differential scanning calorimetry (DSC), and Fourier transform infrared spectroscopy (FTIR). Preliminary in vitro drug dissolution studies for the prepared solid systems were carried out in $0.1 \mathrm{~N} \mathrm{HCl}$ to choose the solid system with superior dissolution characteristics to be incorporated into the fast-release layer present in the proposed DLTs. Matrix tablets containing different concentration grades of HPMC were initially prepared by wet granulation method. ${ }^{12}$ Subsequently, their in vitro release behavior was investigated to select suitable concentrations of HPMC, which are capable of sustaining lornoxicam release, to be employed in the sustained-release layer of the designed DLTs. Finally, DLTs composed of different ratios of sustained- release layer to fast release layer were prepared by wetgranulation method. and their physical properties and in vitro release behavior in simulated gastric and intestinal fluids used in sequence were evaluated. ${ }^{13}$

\section{MATERIALS AND METHODS}

Lornoxicam was received as a gift sample from FD\&C ltd; Roha R\&D. HPMC (K4M, K15M, and K100M) was obtained as gift samples from colorcon, India. B-cyclodextrin, croscarmellose sodium was purchased from yarrow chem. Products, Mumbai. All other materials used were of the best possible laboratory reagents (LR) grade.

\section{Preparation of inclusion complexation of Iornoxicam with $\beta$-cyclodextrin}

To improve the solubility and dissolution behavior of lornoxicam in gastric conditions, lornoxicam was com- plexed with $\beta$-cyclodextrin in different stiochiometric ratios. Inclusion complex were prepared by using kneading method.

\section{Kneading method}

The stoichiometric amounts of lornoxicam and CD were accurately weighed, transferred into a glass motor, and triturated with a small volume of water/ethanol. The obtained slurry was needed for $30 \mathrm{~min}$ and then dried under room temperature. Water/ethanol was used as wetting agent to attain better interaction of drug and $\mathrm{CD}$ during kneading process.

\section{Physicochemical characterizationof lornoxicam - CD complex}

\section{Differential Scanning Calorimetry}

DSC was performed by using $\mathrm{X}$. the apparatus was calibrated with pure indium (99.9\%). Samples (4-5 mg) were placed in an aluminium pan and heated at a constant rate of $10^{\circ} \mathrm{C} / \mathrm{min}$ in presence of nitrogen atmosphere in a temperature range of $20-400^{\circ} \mathrm{C}$.

\section{Solubility studies}

The different stoichiometric ratios were subjected for solubility studies for $72 \mathrm{~h}$ by using higuchi corron's method. And the ratio which is showing the maximum solubility is selected as the best inclusion complex (2:8) is used for further research was given in (Table 1), (Figure 1).

Different stoichiometric rartios of inclusion complexes were prepared by kneading method and their dissolution studies were compared with the pure drug sample (Figure 2). The stoichiometric ratio of 2:8 inclusion complex shows better increased dissolution profile when compared with all the inclusion complexes and pure drug. Based on this data 2:8 inclusion complex was selected and it was used in fast release part of all the formulations of double layered tablet.

\section{Formulation of double layered tablets of lornoxicam}

Double layered tablets is considered as a biphasic drug delivery systems that is formulated in such a way that the drug is released at two different rates and is usually composed of conventional fast release layer and a sustained release layer.

\section{Preparation of fast release layer}

Lornoxicam- $\beta$-CD inclusion complex (2:8) was incorporated in the fast release layer. Along with this croscarmellose sodium is used as a super disintegrant, SCMC as binder, lactose as diluents, FDC No: 6 (sunset yellow) was used as coloring agent and magnesium stearate as lubricant. All the above mentioned ingredients was 


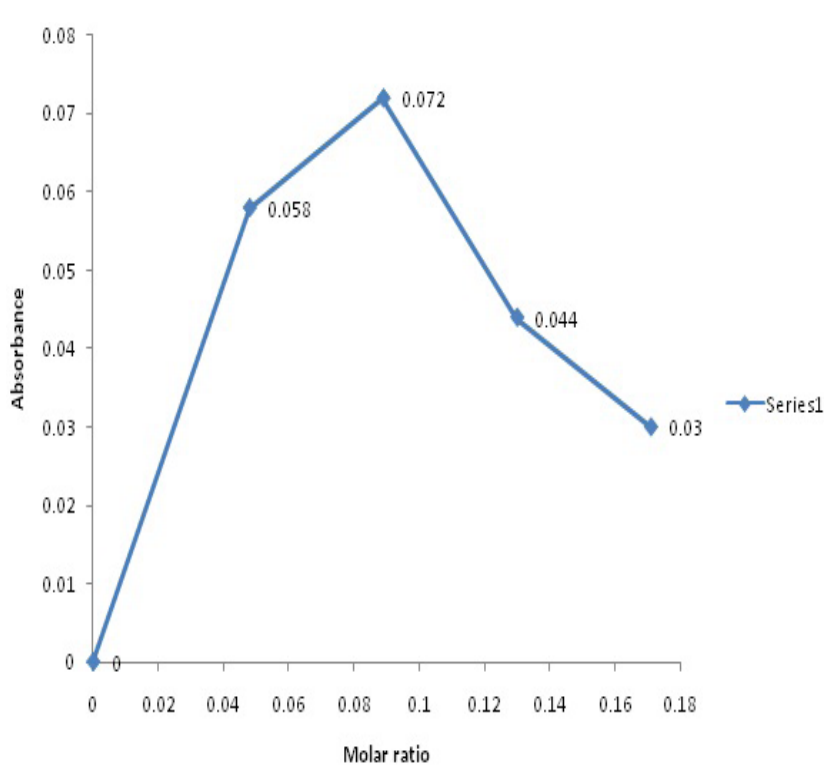

Figure 1: Solubility studies of different complexes

weighed accurately and mixed well for about $30 \mathrm{~min}$ (Table 1).

\section{Preparation of sustained release layer}

Inthe sustained release layer lornoxicam as such is used as active ingredient, along with this three different grades of HPMC (K4M, K15M, K100M) was used as a hydrophilic polymer and SCMC is used as a binder, lactose as diluent and magnesium stearate as lubricant. All the above mentioned ingredients were mixed and the granules were prepared by using SCMC as binder to form a damp mass. The damp mass was then passed through sieve \# 12, the granules are dried at $50^{\circ} \mathrm{C}$ for 30 min. the dried granules were passed through sieve \# 22 to obtain the uniform size of the granules. The dried granules are mixed with magnesium stearate for about 15 min (Table 2).

\section{Characterization of granules}

Prior to compression, the prepared granules were evaluated for their characteristic parameters, such as bulk density, tapped density, carr's index, angle of repose, hausner's ratio. Carr's compress ability index was calculated from the bulk and tapped densities using a digital tapped density apparatus (Electrolab Ltd, India) (Table 3, 4).

\section{Compression of double layered tablets}

Double layered tablets were prepared by using single head rotary tablet compression machine (Rimek, Karnavati). The sustained release granules were placed on the $9 \mathrm{~mm}$ die cavity and was pre-compressed and was then the die cavity was turned to the position, the immediate release granules were placed above the pre-compressed

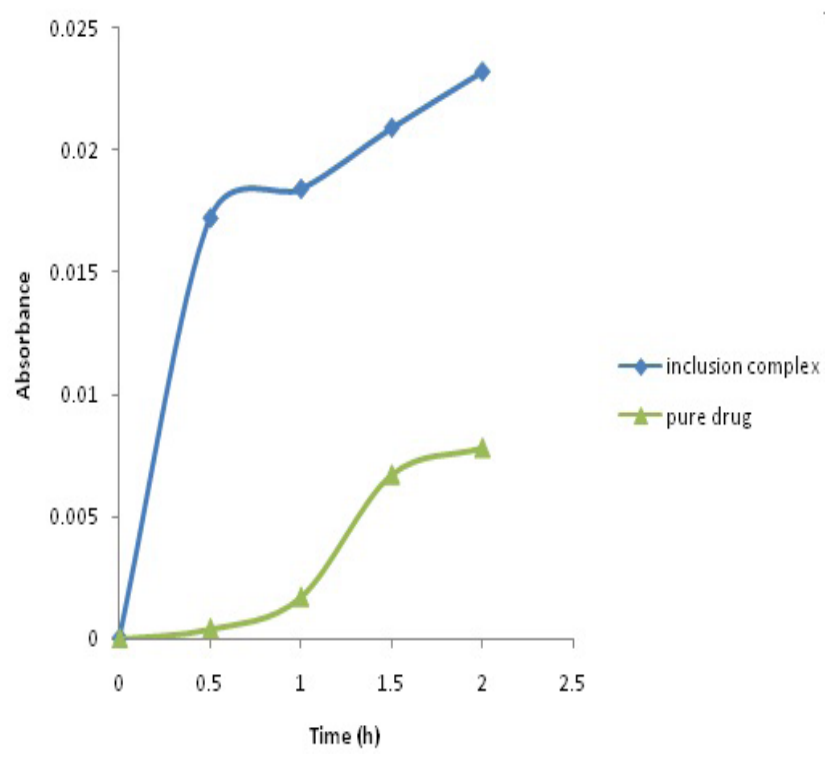

Figure 2: In vitro dissolution comparision of pure drug with inclusion complex

bed of sustained release granules and were subjected for full compression to obtain a intact double layered tablet. The hardness of the double layered tablet was adjusted to $4.5-6.76 \mathrm{~kg} / \mathrm{cm}^{2}$ (Figure 3).

\section{Physical tests for double layered tablets}

Standard physical tests for the double layered tablets were performed and average values were calculated along with their standard deviation. Weight variation was determined by weighing 20 tablets individually, the average weight was calculated and the percent variation of each tablet was calculated. Hardness was determined by taking 6 tablets from each formulation using a Monsanto hardness tester (Electro lab Ltd, India) and the average pressure $\left(\mathrm{kg} \mathrm{cm}^{-2}\right)$ applied for crushing the tablet was determined. Friability was determined by first weighing 10 tablets after dusting and placing them in the Roche's friability tester (Electro lab Ltd, India), which was rotated for $4 \mathrm{~min}$ at $25 \mathrm{rpm}$. After dusting, the total remaining mass of the tablets was recorded and the percent friability was calculated (Table 5).

\section{Drug content uniformity}

Ten tablets were finely powdered and an amount equivalent to $12.3 \mathrm{mg}$ of lornoxicam was accurately weighed and transferred into $25 \mathrm{ml}$ volumetric flast, then $20 \mathrm{mi}$ of 6.8 buffer was added. The flask was shaken and sonicated for $10 \mathrm{~min}$. finally the volume was made with 6.8 buffer. The mixture was then filtered and $1 \mathrm{mi}$ of the filterate was suitably diluted to obtain a solution containing $10 \mathrm{mcg} / \mathrm{ml}$ of lornoxicam and analysed for lornoxicam content at $376 \mathrm{~nm}$ using a double beam UV/ 


\begin{tabular}{|c|c|c|c|c|c|c|c|}
\hline \multicolumn{7}{|c|}{ Table 2: Formulation of the sustained release layer } \\
\hline INGREDIENTS & F-1 & F-2 & F-3 & F-4 & F-5 & F-6 & F-7 \\
\hline Lornoxicam & 8.3 & 8.3 & 8.3 & 8.3 & 8.3 & 8.3 & 8.3 \\
\hline HPMC K4M & 49.95 & 150 & - & - & 25.05 & 25.05 & - \\
\hline HPMC K15M & 49.95 & - & 150 & - & 25.05 & - & 25.05 \\
\hline HPMC K100M & 49.95 & - & - & 150 & - & 25.05 & 25.05 \\
\hline $\begin{array}{c}\text { Sodium } \\
\text { carboxy } \\
\text { methyl cellose }\end{array}$ & 6 & 6 & 6 & 6 & 6 & 6 & 6 \\
\hline $\begin{array}{c}\text { Magnesium } \\
\text { stearate }\end{array}$ & 4 & 4 & 4 & 4 & 4 & 4 & 4 \\
\hline \begin{tabular}{c} 
Lactose (qs) \\
\hline
\end{tabular} & 200 & 200 & 200 & 200 & 200 & 200 & 200 \\
\hline
\end{tabular}

\begin{tabular}{|c|c|c|c|c|c|}
\hline \multicolumn{5}{|c|}{ Table 3: Micromeritic properties of immediate release granules } \\
\hline Formulation code & $\begin{array}{c}\text { Angle of repose } \\
\left({ }^{\circ}\right) \pm \text { SD }\end{array}$ & $\begin{array}{c}\text { Bulk density(gm/ } \\
\mathbf{m l}) \pm \text { SD }\end{array}$ & $\begin{array}{c}\text { Tapped } \\
\text { density(gm/ml) } \\
\pm \text { SD }\end{array}$ & $\begin{array}{c}\text { Carr's index (\%) } \\
\pm \text { SD }\end{array}$ & $\begin{array}{c}\text { Hausner's ratio } \\
\pm \text { SD }\end{array}$ \\
\hline F-1 & $35.39 \pm 3.2$ & $0.39 \pm 0.02$ & $0.45 \pm 0.06$ & $13.07 \pm 2.6$ & $1.15 \pm 0.07$ \\
\hline F-2 & $24.42 \pm .2 .2$ & $0.38 \pm 0.03$ & $0.45 \pm 0.08$ & $14.98 \pm 0.4$ & $1.17 \pm 0.03$ \\
\hline F-3 & $24.09 \pm 1.8$ & $0.38 \pm 0.02$ & $0.43 \pm 0.04$ & $14.11 \pm 1.4$ & $1.13 \pm 0.03$ \\
\hline F-4 & $26.32 \pm 0.8$ & $0.37 \pm 0.04$ & $0.41 \pm 0.05$ & $9.82 \pm 1.3$ & $1.11 \pm 0.01$ \\
\hline F-5 & $25.88 \pm 0.9$ & $0.41 \pm 0.01$ & $0.45 \pm 0.04$ & $8.89 \pm 1.0$ & $1.09 \pm 0.02$ \\
\hline F-6 & $26.91 \pm 1.2$ & $0.41 \pm 0.03$ & $0.45 \pm 0.04$ & $9.98 \pm 2.1$ & $1.10 \pm 0.02$ \\
\hline F-7 & $12.04 \pm 0.4$ & $0.37 \pm 0.04$ & $0.42 \pm 0.04$ & $11.28 \pm 2.7$ & $1.13 \pm 0.01$ \\
\hline
\end{tabular}

\begin{tabular}{|c|c|c|c|c|c|}
\hline \multicolumn{5}{|c|}{ Table 4: Micromeritic properties of sustained release granules } \\
\hline $\begin{array}{c}\text { Formulation } \\
\text { code }\end{array}$ & $\begin{array}{c}\text { Angle of repose }\left(^{\circ}\right) \\
\pm \text { SD }\end{array}$ & $\begin{array}{c}\text { Bulk density(gm/ } \\
\mathbf{m l}) \pm \text { SD } \\
\text { density(gm/ml) } \\
\pm \text { SD }\end{array}$ & $\begin{array}{c}\text { Tapped } \\
\text { Carrs index(\%) } \\
\pm \text { SD }\end{array}$ & $\begin{array}{c}\text { Hausner's ratio } \\
\pm \text { SD }\end{array}$ \\
\hline F-1 & $24.75 \pm 0.16$ & $0.39 \pm 0.01$ & $0.45 \pm 0.03$ & $15.31 \pm 1.14$ & $1.15 \pm 0.02$ \\
\hline F-2 & $26.82 \pm 1.15$ & $0.49 \pm 0.03$ & $0.55 \pm 0.05$ & $10.62 \pm 0.89$ & $1.11 \pm 0.30$ \\
\hline F-3 & $21.30 \pm 0.51$ & $0.42 \pm 0.03$ & $0.44 \pm 0.02$ & $14.86 \pm 1.35$ & $1.05 \pm 0.03$ \\
\hline F-4 & $27.10 \pm 0.44$ & $0.39 \pm 0.09$ & $0.43 \pm 0.04$ & $18.61 \pm 1.78$ & $1.14 \pm 0.01$ \\
\hline F-5 & $30.27 \pm 0.50$ & $0.41 \pm 0.10$ & $0.43 \pm 0.12$ & $15.28 \pm 1.39$ & $1.06 \pm 0.02$ \\
\hline F-6 & $26.25 \pm 0.62$ & $0.44 \pm 0.02$ & $0.46 \pm 0.18$ & $15.03 \pm 2.75$ & $1.05 \pm 0.03$ \\
\hline F-7 & $24.77 \pm 0.76$ & $0.38 \pm 0.04$ & $0.45 \pm 0.09$ & $14.48 \pm 1.14$ & $1.17 \pm 0.07$ \\
\hline
\end{tabular}

Visible spectrophotometer (Shimadzu-1700, Japan) and 6.8 buffer as blank solution.

\section{In vitro dissolution}

Release of lornoxicam was performed by using a USP II six stage dissolution apparatus (Labindia Instruments Pvt Ltd, India) at $50 \mathrm{rpm}$. The dissolution was studied using $200 \mathrm{ml}$ of simulated gastric fluid ( $\mathrm{pH} 1.2$ buffer without enzymes) for first $2 \mathrm{~h}$ and followed by addition of $400 \mathrm{ml}$ of $0.2 \mathrm{M}$ trisodium phosphate phosphate solution to raise the $\mathrm{pH}$ to 6.8 for the remaining hours. The temperature was maintained at $37 \pm 2^{\circ} \mathrm{C}$. the sample $1 \mathrm{ml}$ was withdrawn at different time intervals, i.e 30, 60,90,120,180,240, 300, 360, 420, 480, 540, 600, 660, 720 min respectively, and equal volume was replaced with dissolution medium. Samples were suitably diluted and analysed for lornoxicam content at $376 \mathrm{~nm}$ (Table 6).

\section{RESULTS AND DISCUSSION}

\section{Drug polymer compatibility study}

The drug polymer compatibility studs and analytical investigation of drug by using FTIR and DSC studies showed that there is no interaction between drug and polymer. So, the drug and polymer are compatible (Figure 4, 5).

\section{Preformulation studies}

Estimation of lornoxicam was carried out by SHIMADZU-1700 UV spectrophotometer at $\lambda_{\max } 376 \mathrm{~nm}$ $0.1 \mathrm{~N} \mathrm{NaOH}$ solution. The linear coefficients of each 


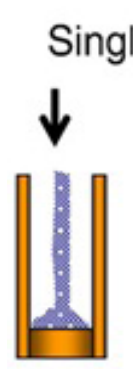

A

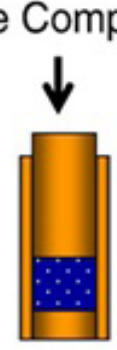

B

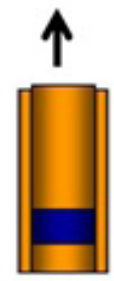

C

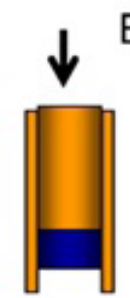

Ejection

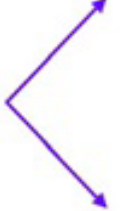

D

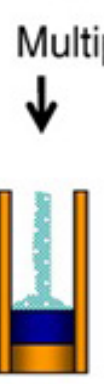

A1

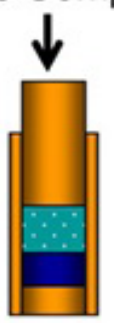

Multiple Compactions
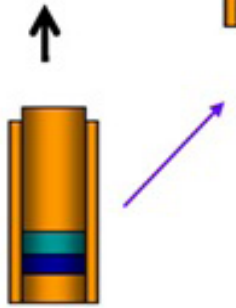

D1

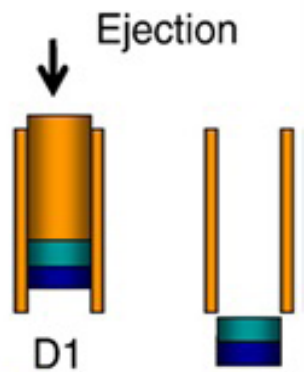

E1

Figure 3: Pictorial representation to prepare double layered tablets

Table 5: physicochemical properties of double layered tablets

\begin{tabular}{|c|c|c|c|c|c|c|}
\hline $\begin{array}{c}\text { Formulation } \\
\text { code }\end{array}$ & $\begin{array}{c}\text { Thickness } \\
(\mathbf{m m}) \pm \mathbf{S D}\end{array}$ & $\begin{array}{c}\text { Hardness } \\
\mathbf{( k g / \mathbf { m m } ^ { 2 } )} \mathbf{\mathbf { S D }}\end{array}$ & $\begin{array}{c}\text { Friability } \mathbf{( \%} \\
\text { loss })\end{array}$ & $\begin{array}{c}\text { Weight } \\
\text { variation } \\
\mathbf{( m g )} \pm \mathbf{S D}\end{array}$ & $\begin{array}{c}\text { Separation of } \\
\text { two layers }(\mathbf{m i n})\end{array}$ & $\begin{array}{c}\text { Drug content } \\
\mathbf{( \% )}\end{array}$ \\
\hline F1 & $4.18 \pm 0.1$ & $7.16 \pm 0.42$ & $0.32 \pm 0.05$ & $296.20 \pm 1.66$ & 21 & $97.56 \pm 1.03$ \\
\hline F2 & $4.20 \pm 0.15$ & $6.56 \pm 0.11$ & $0.37 \pm 0.11$ & $298.68 \pm 0.82$ & 17 & $99.18 \pm 0.89$ \\
\hline F3 & $4.18 \pm 0.15$ & $7.60 \pm 0.34$ & $0.25 \pm 0.05$ & $296.95 \pm 1.06$ & 17.6 & $100.16 \pm 0.68$ \\
\hline F4 & $4.20 \pm 0.20$ & $5.70 \pm 0.30$ & $0.49 \pm 0.08$ & $299.2 \pm 0.74$ & 4.30 & $103.57 \pm 2.19$ \\
\hline F5 & $4.14 \pm 0.25$ & $5.86 \pm 0.14$ & $0.32 \pm 0.10$ & $294.3 \pm 1.32$ & 3.11 & $99.19 \pm 0.89$ \\
\hline F6 & $3.72 \pm 0.05$ & $6.16 \pm 0.56$ & $0.21 \pm 0.13$ & $295.24 \pm 1.21$ & 5.47 & $97.56 \pm 1.86$ \\
\hline F7 & $4.56 \pm 0.11$ & $4.56 \pm 0.04$ & $0.22 \pm 0.05$ & $299.33 \pm 0.69$ & 3.37 & $102.4 \pm 1.17$ \\
\hline
\end{tabular}

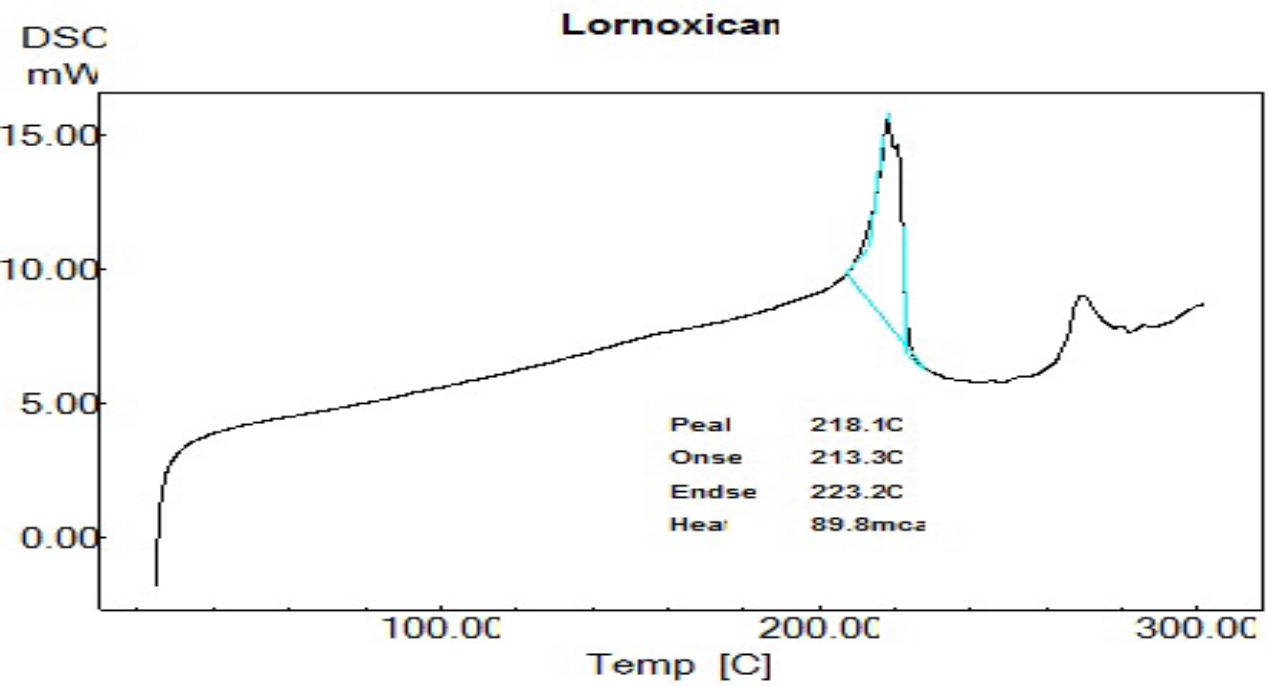

Figure 4: DSC graph of pure drug 


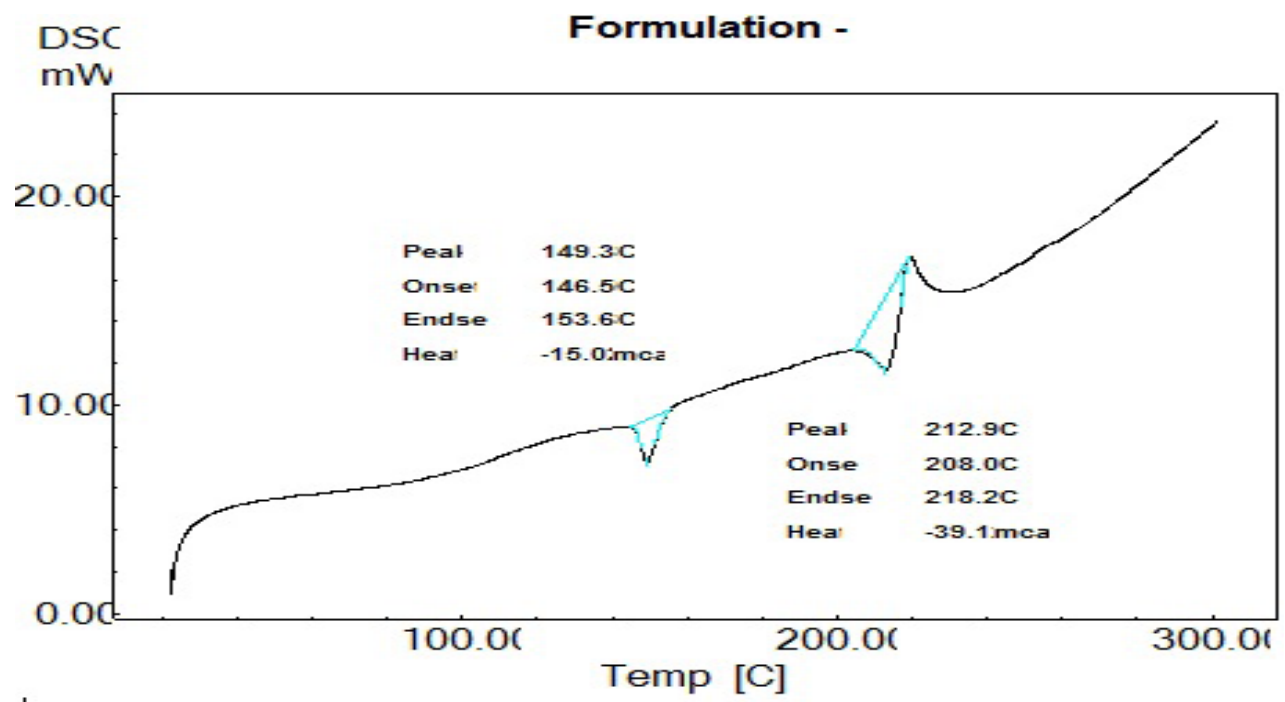

Figure 5: DSC graph of optimized formulation

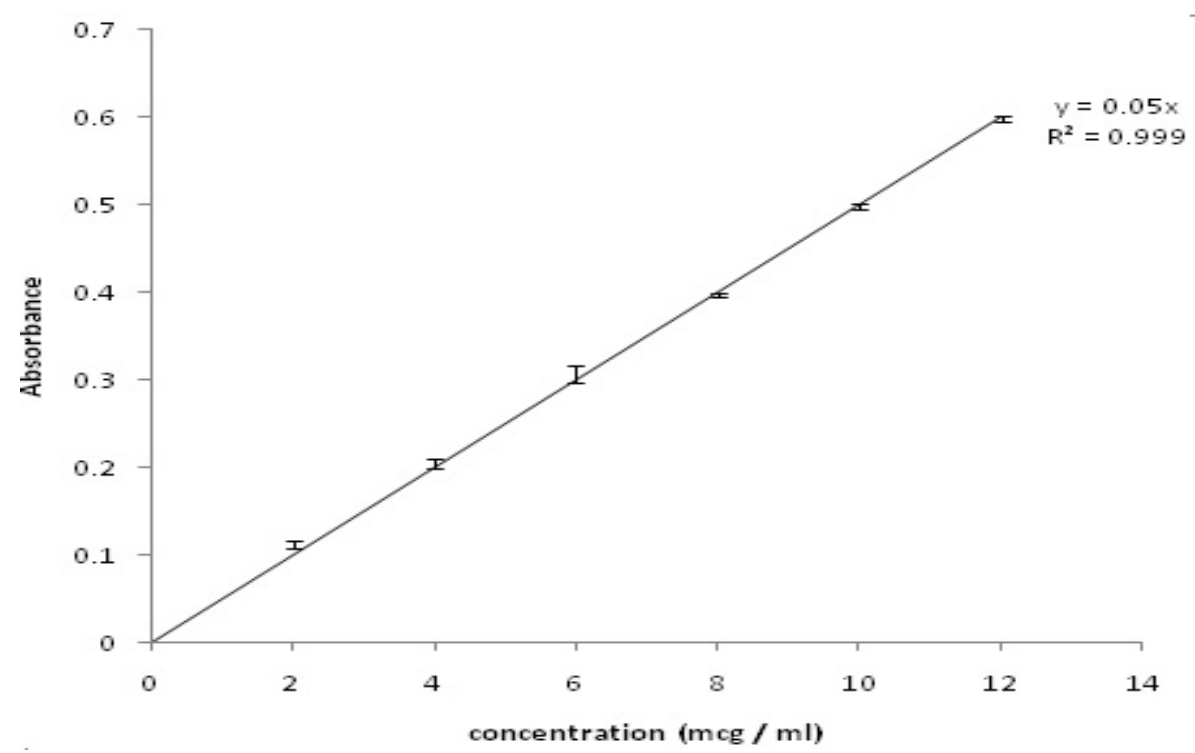

Figure 6: Calibration curve of lornoxicam

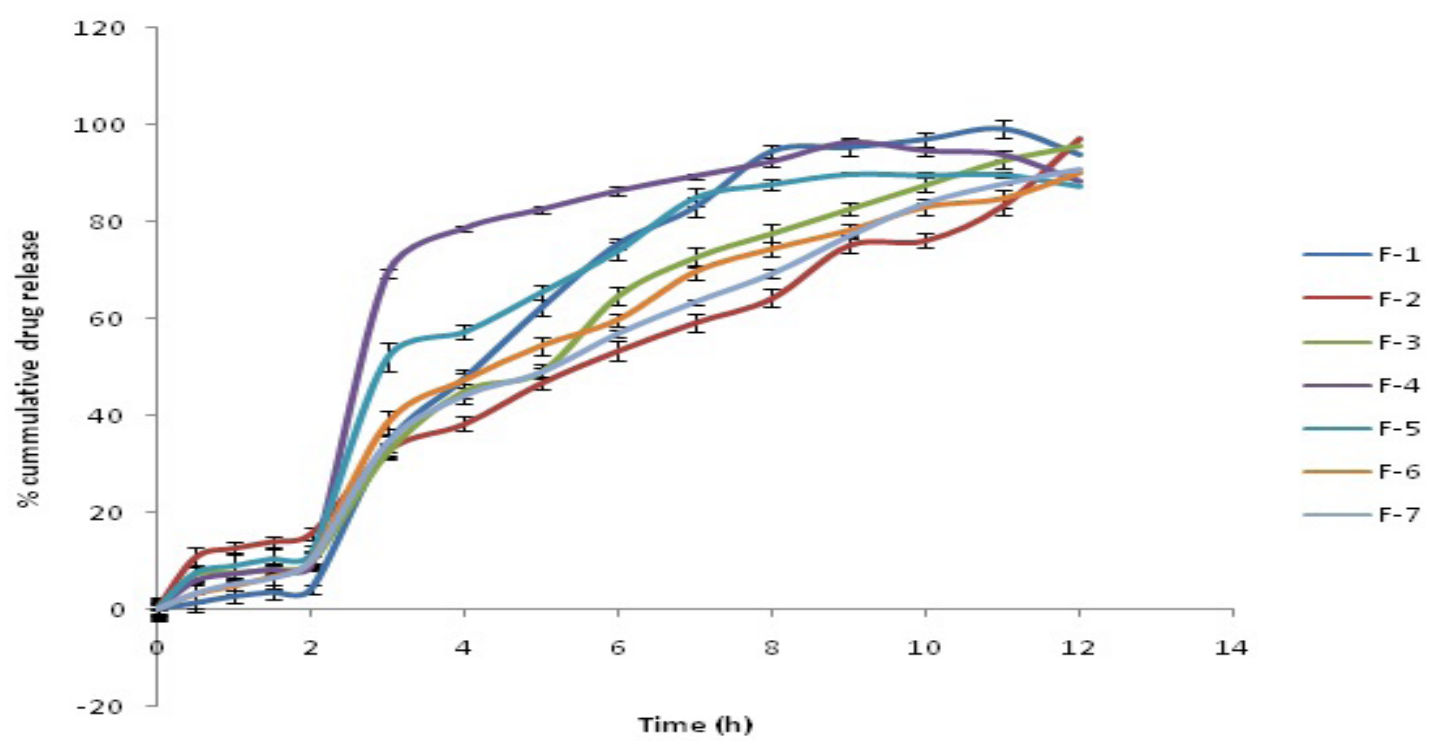

Figure 7: Graph of in vitro release studies 


\begin{tabular}{|c|c|c|c|c|c|c|c|}
\hline \multicolumn{7}{|c|}{ Table 6: in vitro release studies } \\
\hline Time (h) & F1 (\%) & F2 (\%) & F3 (\%) & F4 (\%) & F5 (\%) & F6 (\%) & F7 (\%) \\
\hline $\mathbf{0}$ & 0 & 0 & 0 & 0 & 0 & 0 & 0 \\
\hline $\mathbf{0 . 5}$ & $1.34 \pm 1.54$ & $10.71 \pm 1.23$ & $7.18 \pm 0.48$ & $5.9 \pm 0.17$ & $7.52 \pm 1.88$ & $3.12 \pm 1.11$ & $3.29 \pm 2.38$ \\
\hline $\mathbf{1}$ & $2.68 \pm 1.89$ & $12.57 \pm 1.98$ & $7.54 \pm 0.87$ & $7.28 \pm 0.29$ & $8.96 \pm 1.65$ & $4.81 \pm 2.89$ & $5.22 \pm 1.86$ \\
\hline $\mathbf{1 . 5}$ & $3.54 \pm 1.39$ & $13.95 \pm 1.39$ & $8.23 \pm 0.35$ & $8.27 \pm 0.76$ & $10.41 \pm 2.89$ & $6.74 \pm 1.09$ & $6.42 \pm 2.09$ \\
\hline $\mathbf{2}$ & $4.06 \pm 1.32$ & $15.51 \pm 1.01$ & $9.57 \pm 0.89$ & $8.94 \pm 0.75$ & $11.25 \pm 2.11$ & $9.89 \pm 2.79$ & $9.96 \pm 1.98$ \\
\hline $\mathbf{3}$ & $34.11 \pm 1.09$ & $32.77 \pm 1.22$ & $32.36 \pm 0.12$ & $69.34 \pm 0.36$ & $51.98 \pm 2.01$ & $38.48 \pm 1.79$ & $34.36 \pm 2.05$ \\
\hline $\mathbf{4}$ & $47.69 \pm 1.78$ & $38.25 \pm 1.39$ & $45.09 \pm 0.01$ & $78.57 \pm 0.76$ & $57.24 \pm 2.99$ & $47.26 \pm 2.30$ & $44.06 \pm 2.78$ \\
\hline $\mathbf{5}$ & $62.29 \pm 1.76$ & $46.68 \pm 1.49$ & $49.07 \pm 0.79$ & $82.48 \pm 0.66$ & $65.45 \pm 1.56$ & $54.35 \pm 1.35$ & $48.90 \pm 1.78$ \\
\hline $\mathbf{6}$ & $75.42 \pm 1.59$ & $53.36 \pm 1.37$ & $64.76 \pm 1.87$ & $86.35 \pm 0.87$ & $74.06 \pm 1.45$ & $59.75 \pm 1.89$ & $56.90 \pm 0.98$ \\
\hline $\mathbf{7}$ & $83.05 \pm 1.26$ & $59.16 \pm 1.93$ & $72.67 \pm 1.40$ & $89.36 \pm 0.78$ & $84.93 \pm 1.87$ & $69.57 \pm 1.27$ & $63.38 \pm 0.60$ \\
\hline $\mathbf{8}$ & $94.59 \pm 1.89$ & $64.18 \pm 1.87$ & $77.67 \pm 1.58$ & $92.34 \pm 0.54$ & $87.71 \pm 1.88$ & $74.29 \pm 1.39$ & $69.21 \pm 0.68$ \\
\hline $\mathbf{9}$ & $95.37 \pm 1.27$ & $75.13 \pm 1.89$ & $82.68 \pm 1.20$ & $96.27 \pm 0.79$ & $89.81 \pm 0.97$ & $78.12 \pm 1.49$ & $76.96 \pm 0.98$ \\
\hline $\mathbf{1 0}$ & $97.03 \pm 1.76$ & $76.13 \pm 1.43$ & $87.69 \pm 1.62$ & $94.54 \pm 0.65$ & $89.57 \pm 0.33$ & $82.95 \pm 1.57$ & $83.77 \pm 0.18$ \\
\hline $\mathbf{1 1}$ & $99.19 \pm 1.52$ & $83.26 \pm 1.56$ & $92.71 \pm 1.98$ & $93.75 \pm 0.78$ & $89.71 \pm 0.54$ & $84.69 \pm 1.76$ & $87.72 \pm 0.03$ \\
\hline $\mathbf{1 2}$ & $93.85 \pm 1.78$ & $97.19 \pm 1.88$ & $95.79 \pm 1.73$ & $88.24 \pm 0.99$ & $87.33 \pm 0.38$ & $89.94 \pm 2.02$ & $90.73 \pm 0.11$ \\
\hline
\end{tabular}

\begin{tabular}{|c|c|c|c|c|c|}
\hline \multicolumn{7}{|c|}{ Table 7: Kineticmodeling data } \\
\hline $\begin{array}{c}\text { Formulation } \\
\text { code }\end{array}$ & $\begin{array}{c}\text { Zero order } \\
\left(\mathbf{r}^{\mathbf{2}}\right)\end{array}$ & $\begin{array}{c}\text { First order } \\
\left(\mathbf{r}^{\mathbf{2}}\right)\end{array}$ & $\begin{array}{c}\text { Higuchi } \\
\left(\mathbf{r}^{\mathbf{2}}\right)\end{array}$ & \multicolumn{2}{|c|}{ Peppas } \\
\cline { 5 - 6 } & 0.847 & 0.911 & 0.935 & 0.907 & 0.755 \\
\hline F1 & 0.949 & 0.987 & 0.999 & 0.999 & 0.762 \\
\hline F2 & 0.764 & 0.963 & 0.962 & 0.975 & 0.778 \\
\hline F3 & 0.763 & 0.746 & 0.868 & 0.805 & 0.196 \\
\hline F4 & 0.900 & 0.860 & 0.957 & 0.908 & 0.431 \\
\hline F5 & 0.950 & 0.939 & 0.947 & 0.991 & 0.611 \\
\hline F6 & 0.966 & 0.967 & 0.974 & 0.996 & 0.705 \\
\hline F7 & & & & & \\
\hline
\end{tabular}

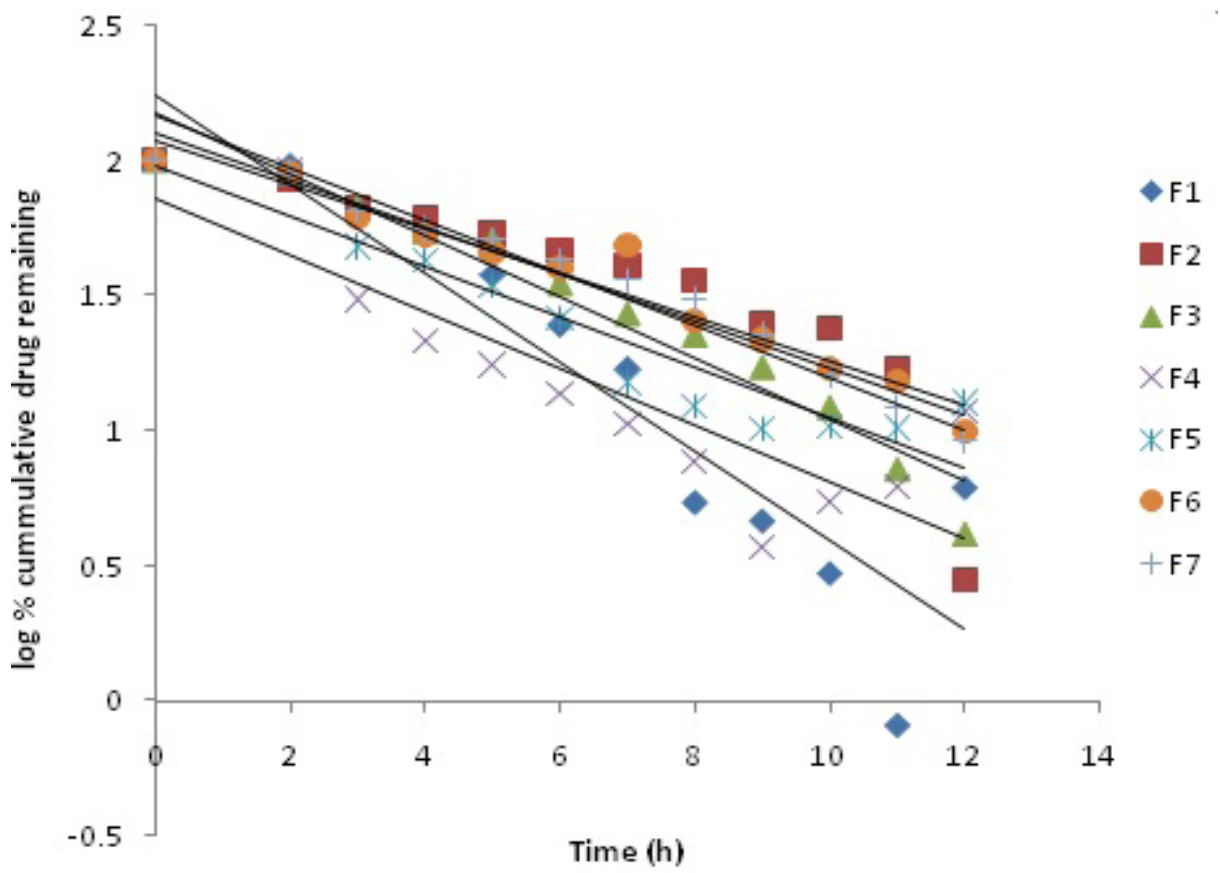

Figure 8: Graph of first order kinetics 
were found closer to 1 . By using the regression coefficient equation the assay and $\%$ CDR were calculated (Figure 6).

\section{UV spectrum analysis of lornoxicam}

At the outset, method for the estimation for the drug was developed. Lornoxicam showed maximum absorption at wavelength $376 \mathrm{~nm}$ in $0.1 \mathrm{~N} \mathrm{NaOH}$ solution. Standard calibration curve obeyed Beer's law at given concentration range of $2 \mu \mathrm{g} / \mathrm{ml}$ to $12 \mu \mathrm{g} / \mathrm{ml}$ and when subjected to regression analysis, the value of regression coefficient was found to be 0.999 , which showed linear relationship between concentration and absorbance.

\section{Micrometric properties of granules}

\section{Angle of repose}

The results of angle of repose were ranged between $21.30^{\circ} \pm 0.51$ to $30.27^{\circ} \pm 0.50$ which indicates good flow properties of powder.

\section{Compressibility index}

The results of angle of repose were ranged between $21.30^{\circ} \pm 0.51$ to $30.27^{\circ} \pm 0.50$ which indicates good flow properties of powder.

\section{EVALUATION OF PHYSICOCHEMICAL PARAMETERS}

\section{Tablet Hardness}

Hardness of the developed formulations F1 to F7 varied from $4.56 \pm 0.04$ to $7.6 \pm 0.34 \mathrm{~kg} / \mathrm{cm}^{2}$ in all the formulation indicating good mechanical strength with an ability to withstand physical and mechanical stress condition while handling.

\section{Tablet Thickness}

Thickness of the developed formulations F1 to F7 varied from $3.72 \pm 0.05 \mathrm{~mm}$ to $4.56 \pm 0.11 \mathrm{~mm}$ in all the formulation and the average thickness is within the range of $\pm 5 \%$. Each sample was analyzed in triplicate.

\section{Friability}

The loss in total weight of the tablets due to friability was in the range of $0.21 \pm 0.13 \%$ to $0.49 \pm 0.08 \%$ in all the formulation and the friability value is less than $1 \%$ which ensures that formulated tablets were mechanically stable.

\section{Weight variation}

The maximum $\%$ deviation was found to be $\pm 2.19 \%$ from all the formulations. As none of the formulation showed a deviation of more than $\pm 5 \%$ (I.P. limit) for any of the tablets tested, the prepared formulations comply with the weight variation test, thus it fulfills the I.P. requirements.

\section{Uniformity of drug content}

The drug content in different tablet formulations was highly uniform and in the range of $97.56 \pm 1.86 \%$ to $103.57 \pm 2.19 \%$. The maximum $\%$ drug content for all the formulation was found to be $103.57 \pm 2.19 \%$. The minimum \% drug content for all the formulation was found to be $97.56 \pm 1.86 \%$. It is in the limits specified by IP (i.e. $\pm 10 \%$ ).

\section{In vitro drug release studies}

The release of lornoxicam from double layered tablets varied according to the types and proportion of matrix forming polymers.

Ideally, a double layered tablet should release the required quantity of drug in order to maintain an effective drug plasma concentration. From in vitro drug dissolution profile of lornoxicam double layered tablet, it was found that $15.51 \pm 1.01 \%$ of the drug was released till $2 \mathrm{~h}$ from F2 formulation. During 2 to $8 \mathrm{~h}$ the marked percentage release was found to be $65 \%$. After $8 \mathrm{~h}$ the release rate decreased slightly and a sustained release pattern was observed for $12 \mathrm{~h}$. The hydrophilic matrix of HPMC controlled the lornoxicam release effectively for $12 \mathrm{~h}$. It was observed that formulation (F2) showed high drug release rates in the range of $97.19 \pm 1.88 \%$. (Figure 7), (Table 6).

\section{KINETIC MODELING OF DRUG DISSOLUTION PROFILES}

The in vitro release data obtained were fitted into various kinetic models. Correlation coefficients of formulation F2 batch showed higher correlation with First order plots than zero order plots, higuchi and peppas were also calculated and the ' $n$ ' value was found to be 0.762 . So, predominant drug release mechanism is Anomalous diffusion (Table 7), (Figure 8, 9,10).

\section{Stability data}

Stability studies were carried out of the most satisfactory formulation $\mathrm{F} 2$, at $30 \pm 2{ }^{\circ} \mathrm{C} / 65 \pm 5 \% \mathrm{RH}$ and $40 \pm 2^{\circ} \mathrm{C} / 75 \pm 5 \% \mathrm{RH}$ for two months to assess their short term stability as per ICH guidelines.

\section{CONCLUSION}

Various formulations were developed by using release rate controlling and gel forming polymers like HPMC (K4M, K15M, K100M) by wet granulation method. Different proportion of HPMC was associated with decrease in the overall cumulative drug release rate. The higher viscosity polymer had been seen to inhibit the initial burst release of lornoxicam. Thus, we conclude that from among all the developed formulations, F2 for- 


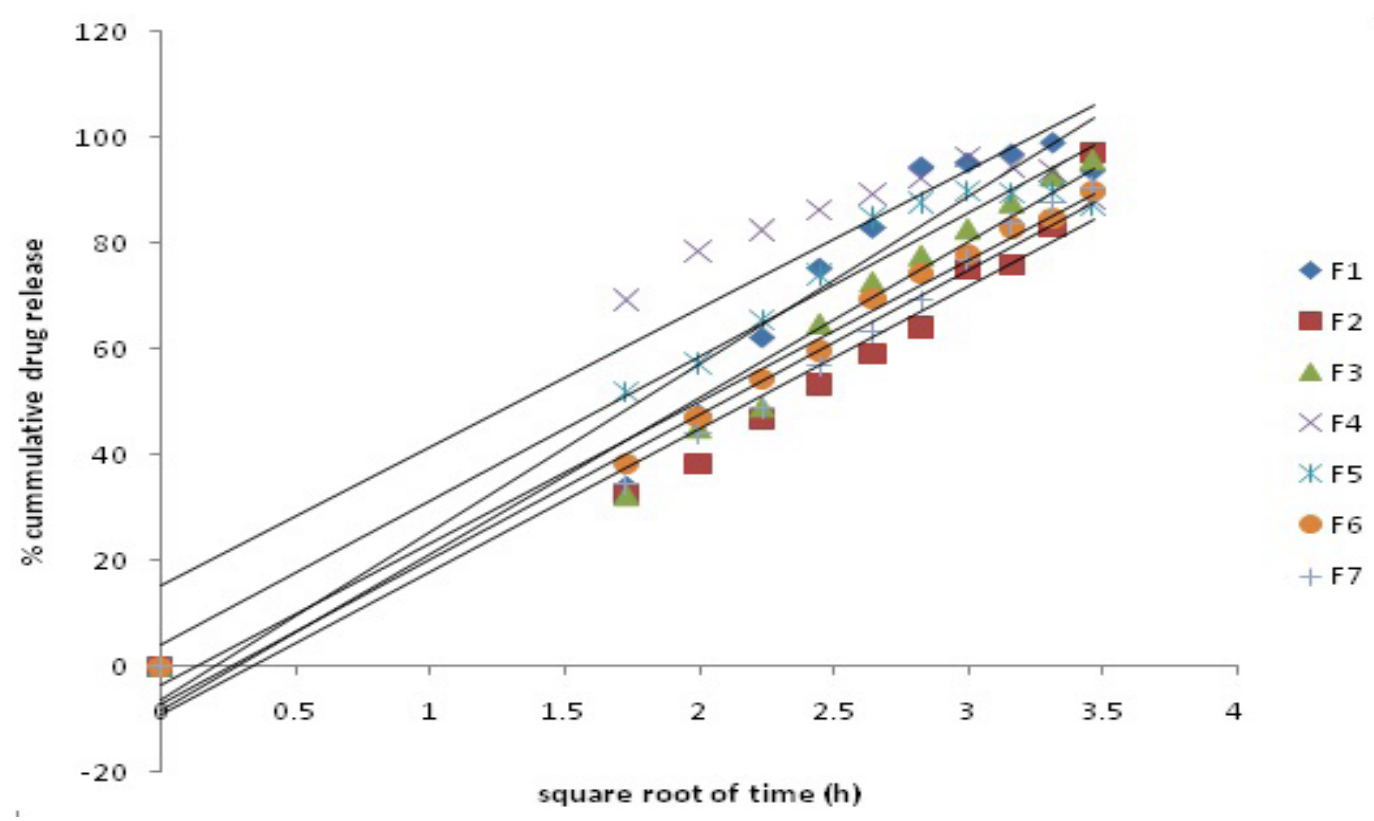

Figure 9: Graph of Higuchi plot

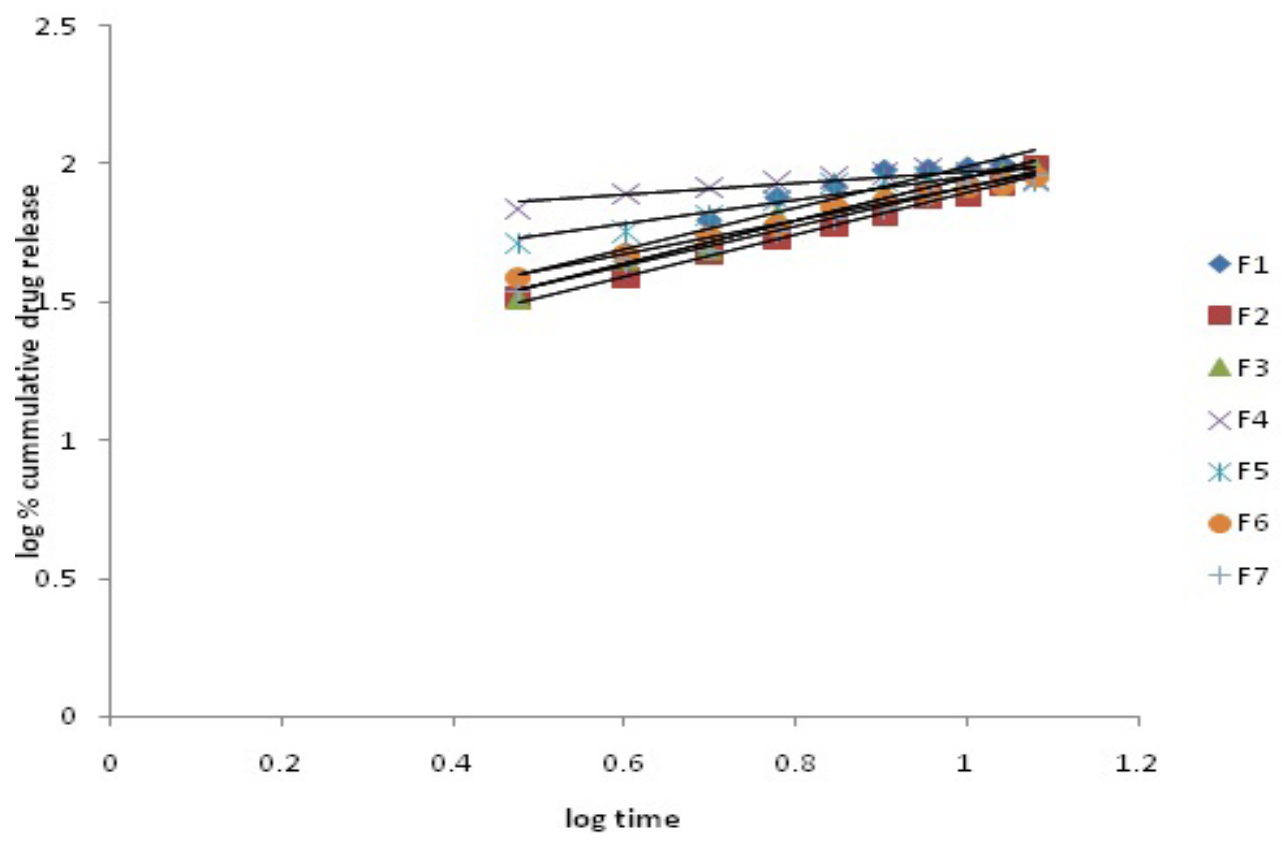

Figure 10: Graph of Peppas plot

mulation sustained the drug release for longer period of time over $12 \mathrm{~h}$ when compare to other formulations. So, F2 was selected as the best formulation which has $\mathrm{HPMC} \mathrm{K} 4 \mathrm{M}$ as a polymer.

\section{ACKNOWLEDGEMENT}

The authors wish to thank Acharya \& BM Reddy College of Pharmacy for providing necessary facilities to carry out the research work. The authors are also thank- 


\section{Highlights of Paper}

- The layered tablet concept has been designed to release the drug at two different rates and is usually composed of a fast-release layer combined with single or double sustained-release lay-ers.

- Various formulations were developed by using release rate controlling and gel forming polymers like HPMC (K4M, K15M, K100M) by wet granulation method.

- The higher viscosity polymer had been seen to inhibit the initial burst release of lornoxicam.

- The release of lornoxicam from double layered tablets varied according to the types and proportion of matrix forming polymers.

\section{Author Profile}

- Dr Shivanand Kalyanappa: Presently working as Associate Professor in Department of Pharmaceutics, Acharya \& BM Reddy College of Pharmacy Bangalore. He has 16 Nos of Research Paper, Presented 6 No of Poster presentation in national conferences; successfully conducted AICTE Sponsored Staff Development Programme, also having two projects from AICTE MODROF and VGST K-Fist L1.

- Dr Divakar Goli: Presently Working as Principal Acharya \& BM Reddy College of Pharmacy Bangalore. He has published more than 100 research papers, presented papers in national and international conferences, received best principal award from APTI in 2013, also received IPA Fellowship award in 2012 from Indian Pharmaceutical Association. He also having number of projects from AICTE.

- Muppa RamKrishna: Completed M. Pharmacy from Acharya \& BM Reddy College of Pharmacy Bangalore. Worked in Geltec pvt ltd Bangalore duration 6 months and Microlabs ltd GOA duration 2 years. Presently working in Optimus generics Hyderabad.

\section{REFERENCES}

1. Merck \& Co. Inc. The Merck index. $13^{\text {th }}$ ed. Whitehouse Station: Merck \& Co. Inc.; 2001.

2. Kumar V, cotran RS, Robbin's SL. Basic Pathology. $7^{\text {th }}$ ed. New Delhi; Reed Elsevier Pvt Ltd; 2003. 771-6.

3. Deodhare SG. General Pathology. $5^{\text {th }}$ ed. Mumbai; Popular Prakasam Pvt Ltd; 1994. 162-295.

4. Martindale. The Complete Drug Reference. $37^{\text {th }}$ ed. London. The Pharmaceutical Press; 2011. 81.

5. Russel Plank. Merck \& Co. Challenges of Multi layer compression for combination products. In AAPS Workshop on Fixed Dose combination products; 2006. Sep 13.

6. Patel M. Challenges in the formulation of Bi layered Tablets: A Review. Int J Pharm Res. 2010; 2(10): 30-42.

7. Jan Vogeleer Paul DE Smet. Bi-Layer Tablets- Why Special Technology is Required. European Pharmaceutical Review 2002; 7(4): 1-6.

8. Raymond CR, Paul JS, Paul WG. Hand book of Pharmaceutical Excipients. $4^{\text {th }}$ ed. Americian Pharmaceutical Association; 2003. 336-40.
9. Nidhi P, Sapkal Vaishali Bharti D, Daud AS. Study of the complexation behavior of fexofenadine with $\beta$-cyclodextrin. Indian J Pharm Sci. 2010; 72(3): 318-23.

10. Shrikant $P$, Dhanyakumar $D$, Rohit $R$. Effect of method of preparation of pioglitazone $\mathrm{HCl}-\beta-C y c l o d e x t r i n$ inclusion complexes. Asian J Pharm. 2010; 4(2): 168-72.

11. Nagori SA, Gohel MC, Parikh RK. Fabrication and evaluation of bi layer tablet containing conventional paracetmol and modified release diclofenac sodium. Indian J Pharm Sci. 2010; 72(2): 191-6.

12. Akiladevi $D$, Jebasingh $D$, Basak $S$. Preparation and evaluation of paracetmol by solid dispersion technique. Int J Pharm Pharm Sci. 2011; 3(1): 188-91.

13. Doile MM, Keila A, Sacha K, Marcos AS, Silva. Physicochemical properties and dissolution studies of dexamethasone acetate- $\beta$-cyclodextrin inclusion complexes produced by different methods. AAPS Pharm Sci Tech. 2008; 9(1): 314-21. 